To cite this Article: Mattila, A. (2016) "The Future Educator Skills in the Digitization Era: Effects of Technological Development on Higher Education," 2015 Fifth International Conference on e-Learning (econf), Manama, 2015, pp. 212-215.

DOI: 10.1109/ECONF.2015.18

URL: http://ieeexplore.ieee.org/document/7478233/ 


\title{
The future educator skills in the digitization era \\ Effects of technological development on Higher Education
}

\author{
Dr. Anssi Mattila \\ Education and Regional Development \\ Laurea UAS \\ Kerava, Finland \\ e-mail: Anssi.m.mattila@laurea.fi
}

\begin{abstract}
Rapid technological development has affected teaching and teachers' work environment in higher education in many ways. Technology allows us to learn anytime, anywhere we want, but are the educators ready and what kind of skills they need to match the changing world. This paper aims to propose points to consider while planning support programs, internal training for higher education teachers in order to help them provide high quality teaching. The main focus is in the direct and indirect effects of digitization. Not all the proposed skills are a necessity in each and every context; instead a higher education institution could use the results of this study to check whether this is something that should be taken seriously in their context. As higher education institutions increasingly offer online courses, teachers' skills have to be up to date, since those skills can be easily globally verified.
\end{abstract}

Keywords-higher education; teaching; skills; digitization; digital competence

\section{INTRODUCTION}

Mobile internet, cloud services, social media, automation, robotics, and IOT/E among others revolutionize organizations' everyday life, and also our private life - higher education institutions won't remain unaffected. It's not unequivocal how tomorrow's work life will turn out to be, because we don't know what kind on unforeseen innovations are waiting for us just around the corner. All that affects the type of students we need to produce for companies to be employed and we need to have capable educators who will guide those students on to the right path. The requirements regarding teachers' skills are not low and the changing world makes sure that we need to update those skills regularly. Maybe there is one skill we can be sure of, namely learning how to learn.

Digitization has raised suspicion about the future of work. Some tend to think that work will disappear (see. e.g. [2]). Work in itself won't disappear; instead it will be reorganized according to the strengths of humans and machines. The characteristics of work still belonging to people will include e.g. intuition, creativity, innovation, social interaction, ethics, morale, politics, motivation, teaching, entertainment, and development of technology. [1]

There are several drivers of change affecting higher education. For example technology is broadly used in K12 schools, which creates expectations for higher education regarding technology use. And globalization calls for internationalization of curricula and implementation of student services for students coming from different cultures and speaking foreign languages. [16][17] All those outside forces affect teachers and the skill requirements. The time cannot be reversed, and teachers have to adapt to these new circumstances.

The second chapter aims to picture the world in which the higher education teachers work today and the third chapter introduces ideas about the skills the teachers could acquire. We concentrate on skills which are mostly either directly or indirectly necessitated by the technological developments.

\section{TEACHERS IN HIGHER EDUCATION}

The skills higher education teachers are expected to have are heavily linked with the skills the students acquire during their studies. How can we teach e.g. Spanish culture if we've seen it only in TV or Java programming if our own skills are on an elementary level? Maybe we can, but can we anticipate good learning results?

Students see that their studies will twine around technology quite tightly in the future. The traditional ways of teaching won't necessarily interest them. Students would readily incorporate the gadgets (e.g. mobile phones, iPads, tablets etc.) they use in their everyday life into teaching. Students expect personalization, 
convenience, and a possibility to plan their studies and choose from many learning options to study according to their own strengths - they want to find their own way [3].

Berry Barnett, Founder and President of the Center for Teaching Quality, Inc. (www.teachingquality.org), has said that relative to other professions, teachers still have to wrestle for status and respect. They are often expected to be smart and entrepreneurial, and also compliant and conforming. [4]

From the management viewpoint $Z$ generation (born 1995-2012, see e.g. [18]) expects quick feedback, challenges, meaningfulness, personalized treatment, fairness and they are open to change [5][6]. Teachers will have to accept this kind of a world and be able to adapt to it. The world where the teachers work can be quite different from the world in which they studied.

In the academic world the idea about learner centered education seems to have spread widely. Educators are supposed to know that different teaching methods together with various educational settings produce different kinds of learning. Teachers' stimulation of learning should have a positive impact on learning outcomes, assessment and recognition. Teachers should be able to deepen students' understanding and knowledge, and develop skills like problems solving, interaction, self-correction, critical reflection, competence improvement, meaning making and experiential learning. [7] It seems quite obvious that teaching won't get any simpler. The reality is heading into the opposite, more complex, direction. In the future we have to focus resources on teaching teachers, and not only in the beginning of their career, but teachers should have a possibility to develop professionally throughout their academic working life.

In the primary and secondary education teachers are supposed to have undergone through pedagogical studies. For some reason this has not been equally acknowledged in higher education. When recruiting a new teacher special focus has been on the academic achievements like publishing activities instead of teaching experience. In the beginning new teachers, even though competent in their own substance, might need assistance in e.g. communication, materials, methods, technology, evaluation, examinations, course structure and pace, and giving feedback. [7][8]

If teaching is not regarded as valuable function as research, it might prove difficult to get teachers committed to develop professionally as teachers - not only as researchers. In addition to being able to produce good quality learning material, which could be seen as a link to research, teacher's knowledge base ought to be wider than the substance he/she's teaching. Higher education institutions are supposed to support teaching staff through different means - continuous education and training, individual mentoring, coaching, strengthening team work of teachers in designing, developing and delivering curricula and assessing student performance [7].

A Delphi-study completed among 70 experts (Germany, Great Britain, Ecuador, Chile and Mexico) reflects on the skill requirement of the students from the viewpoint of sustainable development. In the experts' opinion the most important key competencies were systemic thinking and handling of complexity, competency for anticipatory thinking and critical thinking. Also regional and cultural particularities are of importance. [9] It's not self-evident that a teacher can deliver these skills to students. However, if we want our students to excel in their career we need to be able to help them with these skills.

In 2001 current (even today) expectations for educational system were presented. An educational system should provide students with skills like: [10]

- Coping with rapid change, aging of knowledge and skills.

- Ability to question the consequences of change, and ability to analyze scientific findings and technological innovation regarding ethicalness and practical future effects.

- Ability to live in the digital era and ability to apply appropriately rapidly changing information and communication technologywhile considering the challenges created by social networks and applicable teaching and learning methods in the young digital culture.

- Awareness of dangers of increasing inequality related to social cohesion, peace and democracy inside and among countries, and increasing xenophobia, racism, and intolerance.

It's also important to recognize the fact that learning by doing things is an elementary part of learning. In the early phase of a professional career it might be possible that automation decreases the opportunities to learn by practically doing something [1][11]. For higher education students the opportunity to gain work experience during the studies might be highly beneficial and also for the companies recruiting them after the graduation. One could assume that the higher education institutions should support the cooperation of teachers and 
businesses, since the stronger the relationship between the businesses and the teachers, the stronger is the validity of education and training regarding the expectations of companies. If teachers stay connected to the life outside the university, they should have more tools to support the students in their path to the future professionals.

Technology enables virtual faculties, where it's feasible to have the best students and teachers from around the world. The Internet, clouds, streaming, and technologies alike create challenges for a formal educational system. Technology furthers the ways of teaching and learning. Massive open online courses, blended teaching and learning are just a couple of examples of technology's impact. Information and skill acquisition is not up to the place and the time anymore. The student and teacher roles are being redefined and especially online teaching calls for new skills from the teachers.

People expect to be able to work, learn, and study anytime and anywhere. Technologies, like mobile technologies, help the emergence of these kinds of expectations. E.g. airlines have acknowledged these needs by offering a wireless Internet connection on board. All this concerns higher education as well. Teachers have to be flexible about their working hours and the line between work and free time will continue to obscure. [12]

Electronic books and mobile devices have been in use in higher education for a longer period already. Augmented reality and game-based learning have gained ground recently. Gesture-based computing and learning analytics are being utilized by some of the institutions. [12] In addition to updating skills and knowledge regarding the substance to be taught, a teacher has to manage pedagogy and the pedagogy related technology.

\section{SKILL REQUIREMENTS}

Because of the technological developments and the tendency of offering more and more courses online we need to pay special attention to the effects of digitization. And it's self-evident that all the requirements don't apply to all the circumstances. One needs to consider own environment and analyze what should be applied there.

The skill requirements of teachers involved especially in online teaching and blended teaching could include: - Digital competence

- Language and cultural competence

- Communication skills, social intelligence, soft skills

- Pedagogy and pedagogical tools

- Ability to manage the line between work and free time

- Problem solving, anticipatory and critical thinking, "meaning making"

Digital competence can be seen as a key competence, which helps acquiring other key competencies like language, math, learning to learn, cultural awareness etc. Digital competence can broadly be defined as the confident, critical and creative use of ICT to achieve e.g. work related goals. [13] This is an essential skill for today's teachers, since they have to manage several substances from the one taught to the pedagogical tools. Digital competence helps teachers to acquire and update skills needed in their work.

The significance of language and cultural skills, and also soft skills (see. e.g. [14]), increase all the time as higher education institutions recruit staff abroad and try to entice foreign students to participate in their online courses or to become a student studying at their campuses. As technology more and more comes between a teacher and a learner, teachers have to be especially sensitive regarding communication in order to avoid any unnecessary misunderstandings. Also different cultural backgrounds call for concentration on understanding cultural differences.

In order to deliver good quality face-to-face, blended and online teaching a teacher should get familiar with pedagogy related tools, basically any tools, which can be used in the teaching context. Gamification, puzzles, hangman games etc. can be of great help in teaching if applied sensibly, see e.g. [15]. The new generation expects personalization and entertainment even in the education; in here only teachers' imagination sets the limits. The Internet offers a great number of usable and free tools to be utilized in teaching. Online teaching is quite different from the normal, everyday class action. Teachers should get familiar with good and tested practices related to online education.

Flexibility, personalization, quick and to the point feedback, calls for flexibility and understanding regarding time management. When teaching face-to-face the time e.g. for the feedback is pretty much set, but in an 
online environment, where learners can individually progress with their studies, it might be that the teachers have to be at the students' disposal during unforeseen hours. If availability expectations are not communicated to the students clearly, this might result in students' frustration.

Ability to solve problems, anticipatory and critical thinking, and meaning making are skills we want to deliver to higher education students. To be able to teach these skills, a teacher has to manage those by him/herself. It's often said that these skills are in high demand, but is it obvious that the teachers are competent in this area?

Huge number of technological innovations and developments in various areas creates a situation, where teachers have to be able to see sense behind all that. We can't try to teach everything to our students, instead we need to make intelligent choices as we go on. Less can be more in online environment too.

\section{CONCLUSION}

Digital competence is a skill required in many professions in addition to teaching. It helps in acquiring new skills and updating the old. If you were to prioritize, digital competence is evidently a beneficial skill for the teachers in higher education. Globalization makes sure that new cultures and languages touch the lives of an increasing number of people. Language, cultural skills are in demand and soft skills balance the technology oriented focus. Institutions should not neglect the language and culture issues while aiming to provide quality education for todays' higher education students. Pedagogical competence is seen as an important part of teachers skill set. Even if you were a top programmer, it does not mean that you are able to help your students learn that skill.

\section{REFERENCES}

[1] M. Pajarinen \& P. Rouvinen, Uudet teknologiat ja työ, In "Katsaus suomalaisen työn tulevaisuuteen", Ministry of Employment and Economy, Työ ja yrittäjyys, 30/2014, p. 33-52.

[2] URL: http://www. dailymail.co.uk/news/article-2826463/CBREreport-warns-50-cent-occupations-redundant-20-years-time.html. Downloaded Jun 052015

[3] M. Van Der Werf, G. Sabatier, The Colloge of 2020; Students,Chronicle Research Services, http://www.uwec.edu/CETL/bundles/ upload/college2020-dl.pdf, 2009.

[4] B. Barnett, The Future of Teaching Profession, URL: http://www. divinecaroline.com/life-etc/culture-causes/future-teachingprofession.

[5] K. Higginbottom, Managing generation Z, URL: https://www.i-Im.com/Insight/Edge/2013/Apri//managing-generation-z.

[6] URL: http://www.muc.fi/z-sukupolven-johtaminen-on-maalaisjarjenkayttoa.

[7] Report to the European Commission on Improving the quality of teaching and learning in Europe's higher education institutions, High Level Group of the Modernisation of Higher Education, 2013.

[8] R. Lattuca, P. T. Terenzini, D. B. Knight \& H. K. Ro, 2020 Vision: Progress in Preparing the Engineer of the Future, URL: http://deepblue.lib.umich.edu/bitstream/handle/2027.42/107462/2020\%20Vision\%20FINAL.pdf?sequence=5\&isAllowed=y

[9] M. Rieckmann, Future-oriented higher education: Which key comptencies should be fostered through university teaching and learning, Futures, 03/2012, Volume 44, Issue 2.

[10] A. Michel, Schools for an emerging world, in: What schools for the future? Paris, OECD, p. 217-229, 2001.

[11] J. D. Sachs \& L. J. Kotlikoff, Smart Machines and Long-Term Misery, NBER Working Papers, 18629, 2012.

[12] L. Johnson, R. Smith, H. Willis, A. Levine \& K. Haywood, The Horizon Report, Austin, Texas, USA: The New Media Consortium, 2011.

[13] A. Ferrari, Digital Competence in Practice: An Analysis of Frameworks, European Commission, Joint Research Centre, JRC Technical Reports, ISBN 978-92-79-25039-4, 2012.

[14] N. Sultana, Soft Skills for Employability, International Journal of Organizational Behaviour \& Management Perspectives, Volume 3 , Number 1, 2014.

[15] http://www.warrensburgr6.org/education/components/scrapbook/default.php?sectiondetailid=19832\&

[16] T. Futhey, R. Luce \& J. M. Smith, Drivers of change in Higher Education, Educause Review, 45(1), p. 12-13.

[17] P. J. Goldstein, The Future of Higher Education: A view from CHEMA, URL: http://net.educause.edu/ir/library/pdf/ECP0602.pdf.

[18] http://www.socialmarketing.org/newsletter/features/generation3.htm 